\title{
Adiposity and Cognitive Decline in the Cardiovascular Health Study
}

\author{
José A. Luchsinger ${ }^{a}$ Mary L. Biggs ${ }^{c} \quad$ Jorge R. Kizer ${ }^{b} \quad$ Joshua Barzilay ${ }^{g}$ \\ Annette Fitzpatrick $^{d} \quad$ Anne Newman $^{\text {h }}$ William T. Longstreth ${ }^{\mathrm{e}}$ Oscar Lopez ${ }^{\mathrm{i}}$ \\ David Siscovick $^{f}$ Lewis Kuller $^{\mathrm{j}}$ \\ ${ }^{a}$ Departments of Medicine and Epidemiology, Columbia University Medical Center, and ${ }^{\mathrm{b}}$ Department of Medicine \\ and Department of Epidemiology and Population Health, Albert Einstein College of Medicine, Bronx, N.Y., \\ 'Department of Biostatistics, School of Public Health, ${ }^{d}$ Collaborative Health Studies Coordinating Center, \\ e Departments of Neurology and Epidemiology, and ${ }^{f}$ Cardiovascular Health Research Unit, Departments of Medicine \\ and Epidemiology, University of Washington, Seattle, Wash., ${ }^{9}$ Kaiser Permanente, Tucker, Ga., and Departments of \\ hEpidemiology and Medicine, 'Neurology and ${ }^{\mathrm{j} E p i d e m i o l o g y, ~ U n i v e r s i t y ~ o f ~ P i t t s b u r g h, ~ P i t t s b u r g h, ~ P a ., ~ U S A ~}$
}

\section{Key Words}

Adiposity $\cdot$ Bioelectrical impedance $\cdot$ Body mass index $\cdot$

Cognition $\cdot$ Fat mass $\cdot$ Waist circumference

\begin{abstract}
Background: Studies relating adiposity to cognition in the elderly show conflicting results, which may be explained by the choice of adiposity measures. Thus, we studied the longitudinal associations of different adiposity measures, fat mass by bioelectrical impedance analysis, body mass index (BMI) and waist circumference (WC), with cognitive performance in the Cardiovascular Health Study. Methods: Cognitive performance was assessed with the modified Mini-Mental State Examination, the Digit Symbol Substitution Test, and a composite of both. We used linear mixed models to estimate rates of change in cognitive function scores associated with adiposity measured at baseline. Results: The final sample was comprised of 2,681 women (57.9\%) and 1,949 men (42.1\%) aged $73 \pm 5.2$ and $73.9 \pm 5.6$ years, respectively. Adiposity was associated with slower cognitive decline in most analyses. Results were similar for fat mass, BMI and WC. Higher fat-free mass was also related to slower cognitive decline. Results were similar in analyses excluding persons with
\end{abstract}

\section{KARGER}

E-Mail karger@karger.com

www.karger.com/ned cancer, smokers, and persons with short follow-up, poor selfreported health, or persons with cardiovascular disease. Conclusions: Higher adiposity and higher fat-free mass in the elderly was related to better cognitive performance. This finding was not explained by confounding by preexisting conditions.

Copyright $\odot 2013$ S. Karger AG, Basel

\section{Introduction}

Cognitive impairment is increasing in our aging societies [1] without known cure or prevention [2]. Half of the persons aged 85 years and older have dementia [3] and a fifth of the persons 70 years and older have non-dementia cognitive impairment [4]. Adiposity has emerged as a potential modifiable risk factor [5], and this is alarming because most adults in the United States have elevated adiposity [6].

Higher middle-age adiposity is associated with cognitive impairment in old age [7-11], but studies assessing adiposity in older age show conflicting results. These studies show associations between elevated body mass index (BMI) and higher dementia risk [12], inverse associa- (c) 2013 S. Karger AG, Basel

0251-5350/13/0404-0274\$38.00/0 
tions [7, 13], and non-linear [14] or no associations [15]. A potential explanation for these conflicting findings is that BMI is the best adiposity measure in the elderly. Thus, we compared the association between different baseline adiposity measures and cognition longitudinally in the Cardiovascular Health Study (CHS).

\section{Methods}

CHS is a population-based cohort study of cardiovascular disease in older adults. In 1989-1990, 5,201 ambulatory, non-institutionalized men and women aged 65 years and older were recruited from a random sample of Medicare-eligible residents in four US communities: Forsyth County, North Carolina; Sacramento County, California; Washington County, Maryland, and Allegheny County, Pennsylvania. A supplemental cohort of 687 predominantly African-American men and women was recruited during 1992 and 1993 from three of the same communities (excepting Washington County) using the same sampling and recruitment methods. Each center's institutional review committee approved the study and all participants gave written informed consent. Details on the study methods have been published previously $[16,17]$.

We excluded 108 persons without bioelectrical impedance analysis (BIA) data, 267 without cognitive scores, 191 without follow-up, 6 because of implausible adiposity values, and 686 with missing covariates (666 did not provide consent for analysis of genetic data for non-CVD endpoints and were missing information on apolipoprotein $\mathrm{E} \varepsilon 4$ (APOE- $\varepsilon 4$ ) genotype. The final sample was comprised of 4,630 participants.

Participants underwent a comprehensive baseline evaluation including questionnaires, physical examination, anthropometry, cognitive assessment, and laboratory testing. Descriptions of data collection methods have been reported previously [17].

\section{Body Composition Measures}

Trained personnel performed anthropometric measurements using standardized protocols. Participants wore standard examination suits and no shoes. Standing height was measured using a stadiometer calibrated in centimeters. Body weight was measured using a balance beam scale calibrated in kilograms. Waist circumference (WC) was measured at the umbilicus. BMI was calculated as weight (kilograms) divided by height squared (square meters). BIA was conducted at baseline with participants in a supine position using a TVI-10 body composition analyzer (Danninger Medical, Columbus, Ohio, USA). Four adhesive electrocardiograph electrodes were placed in standard distal positions on the dorsum of the right hand and foot and resistance was measured at $50 \mathrm{kHz}$. Fat-free mass was calculated as 6,710 $\times$ height $^{2} / \mathrm{R}+3.1 \times \mathrm{S}+3.9$, where height ${ }^{2}$ is standing for height in meters squared, $\mathrm{R}$ is resistance in ohms, and $S$ is sex ( $0=$ females, $1=$ males) [18]. Fat mass was calculated as body weight minus fat-free mass. Body composition measures were categorized as sex-specific quintiles.

\section{Cognitive Measures}

Cognitive function was measured annually during in-person visits from 1990 to 1999 using the 100-point modified Mini-Men- tal State (3MS) examination [19] and the Digit Symbol Substitution Test (DSST). The 3MS and the DSST were the primary outcomes in these analyses. The $3 \mathrm{MS}$ is a measure of global cognition. The DSST is a measure of executive cognitive abilities. Beginning in 1996, participants who did not attend the in-person visit were contacted by phone and asked to complete the Telephone Interview for Cognitive Status (TICS), a brief telephone interview consisting of 11 items designed to identify cognitive impairment in Alzheimer's disease patients [20]. The TICS was used to impute missing 3MS data. We generated a composite cognition score by first standardizing $3 \mathrm{MS}$ scores and DSST scores (by subtracting the mean and dividing by the standard deviation of each respective test) and then adding together the standardized scores for each participant.

\section{Other Covariates}

Age, gender, race, years of education, and smoking were based on self-report. Diabetes was identified on the basis of a fasting glucose concentration of $\geq 126 \mathrm{mg} / \mathrm{dl}$ or use of diabetes medications. APOE- $\varepsilon 4$ genotyping was performed using the method of Hixson and Vernier [21] only for participants who provided consent for genetic analysis.

\section{Statistical Analysis}

We calculated Spearman correlation coefficients for pairs of adiposity measures. We categorized participants by sex-specific quintiles of BMI, WC, and fat mass by BIA, using the lowest quintile as the reference group.

Previous research in CHS has indicated that participants experiencing greater cognitive decline were less likely to participate in the in-person visits [22]. To minimize the influence of this type of non-participation on the assessment of cognitive function over time, we used a regression model based on the TICS developed and validated in CHS [22] to estimate missing 3MS scores during 1996-1999. A total of 1,052 out of a total of 33,068 (3\%) 3MS scores were imputed among participants with TICS scores missing 3MS scores at one or more annual assessments. No such model was available for the DSST, and DSST analysis included only observed scores.

We used linear mixed models to examine the association between baseline adiposity measures, categorized as sex-specific quintiles, and change in cognitive scores from 1990 to 1999. Separate models were fit for BMI, WC, fat mass, and fat-free mass. All models were adjusted for baseline age, gender, race (black, nonblack), educational attainment (<high school, high school or more), field center, baseline smoking (never, former, current), and APOE- $\varepsilon 4$. Models were not adjusted for variables considered mediators between adiposity and cognitive decline, such as diabetes. Three output categories are presented: (1) main effect coefficients and 95\% confidence intervals (CI) comparing cognitive scores across quintiles of adiposity measure using the first (lowest) quintile as the reference; (2) the coefficient and 95\% CI for time, and (3) the coefficient and 95\% CI for the interaction term of adiposity quintile and time. Coefficients of the main effect adiposity terms are interpreted as the average point difference in baseline cognitive scores between each adiposity category and the reference group. The time coefficient is interpreted as the average annual change in cognitive scores over follow-up in the reference group (e.g. a negative coefficient indicates decline in scores over time). The coefficient of the adiposity by time interaction is inter- 
preted as the average annual difference in slopes (rates of change in scores) between participants in each adiposity category compared to the reference. For example, if the coefficient for time is -1 (indicating an average decline of 1 point per year in the reference group), and the coefficient for the interaction term of time and the fifth quintile of an adiposity measure is 0.25 , this indicates that cognitive decline was less pronounced in the fifth quintile compared to the reference by 0.25 points.

We conducted sensitivity analyses to address potential biases. We excluded current smokers (521), persons with a history of cancer (237), persons with incident cancer (214), persons who died in the first 3 years of follow-up (76), and persons who were lost to follow-up in the first 3 years (128). We also restricted our analyses to 3,017 persons with reported good health, including never smokers, excellent, good, or very good self-reported health, and no reported unintentional weight loss. Finally, we conducted analyses in 4,454 persons without reported congestive heart failure at baseline and in 3,933 persons without congestive heart failure, myocardial infarction, or stroke at baseline. Statistical analysis was performed using Stata software version 10.1 (StataCorp, College Station, Tex., USA).

\section{Results}

The final sample included 2,681 women (57.9\%) and 1,949 men $(42.1 \%)$ aged $73.0 \pm 5.2$ and $73.9 \pm 5.6$ years, respectively. Table 1 shows general characteristics by BMI and sex categories. $\mathrm{BMI}(\mathrm{r}=0.80$ and $\mathrm{r}=0.90$, among men and women, respectively) and WC $(r=0.81$ and $r=0.77)$ were strongly correlated with fat mass, while fat-free mass $(\mathrm{r}=0.23$ and $\mathrm{r}=0.43)$ was modestly correlated. Fasting insulin, glucose, low-density lipoprotein, C-reactive protein, and interleukin 6 , all increased with increasing adiposity quintiles (fat mass, BMI, WC), while high-density lipoprotein decreased ( $\mathrm{p}<0.0001$ for all associations).

Tables 2 and 3 show the results of longitudinal analyses. As expected, 3MS, DSST, and composite scores decreased over time, indicated by a statistically significant negative time coefficient. A summary of results from adjusted analyses by each adiposity measure follows.

Body Mass Index. For the 3MS, only the baseline score of the 4th quintile was positive and statistically significant, indicating higher scores, compared to the first quintile (table 2). All interaction terms were positive, indicating that compared to the lowest BMI, the higher quintiles had slower decline in $3 \mathrm{MS}$ scores over follow-up. For the DSST, BMI quintiles were not related to baseline scores. Only the interaction term for the 5th quintile of BMI was statistically significant and positive, indicating that compared to the first BMI quintile, the 5th quintile had a slower decline in the DSST. For the composite scores, $\mathrm{BMI}$ quintiles were not related to baseline scores. The in- teraction terms for the 4 th and 5th quintiles of BMI were positive and statistically significant, indicating that decline in the composite scores was slower for the highest BMI quintile compared to the lowest one.

Waist Circumference. For the 3MS, WC quintiles were not associated with baseline scores (table 2). The interaction terms for the 2nd, 4 th and 5th WC quintiles were positive and statistically significant, indicating that compared to the 1st quintile, a higher WC quintile was related to slower decline. For the DSST, there was no association between WC quintiles and the baseline scores. The interaction terms were not statistically significant, indicating that there was no difference in decline among WC quintiles. For composite scores, there was no association between WC quintiles and the scores. Only the interaction term for the 4th WC quintile was positive and statistically significant, indicating that composite score decline was slower for the 4 th quintile compared to the first quintile.

Fat Mass. For the 3MS, higher fat mass was associated with higher baseline scores for the 2nd, 3rd, 4th and 5th quintiles compared to the 1st (table 3 ). All the interaction terms were positive and significant indicating less decline with higher fat mass. For the DSST, fat mass was not associated with baseline scores. Interaction terms for the 4 th and 5th quintiles were positive and statistically significant, indicating slower decline with higher fat mass. For the composite score, higher fat mass was associated with higher baseline scores for the 2nd, 3rd, 4th and 5th quintiles compared to the 1st. All the interaction terms were positive and significant indicating less decline with higher fat mass.

Fat-Free Mass. For the 3MS, the 3rd, 4 th, and 5th quintiles were associated with higher baseline scores compared to the first quintile (table 3). The interaction terms for all fat-free mass quintiles were positive and significant, indicating that those with higher fat-free mass showed slower decline compared to the first quintile. For the DSST, baseline scores were higher in the 3rd quintile of fat-free mass compared to the first quintile. None of the interaction terms were significant indicating that fat-free mass was not related to decline. For the composite score, the $3 \mathrm{rd}, 4$ th and 5th quintiles were associated with higher baseline scores. The interaction terms were positive and significant for the $2 \mathrm{nd}$, 3rd and 5th quintile, indicating a slower decline with higher fat-free mass compared to the first quintile.

Sensitivity analyses for all adiposity measures showed associations in the same direction and with similar effect estimates as for the main analyses. 
Table 1. Demographic, medical, and lifestyle characteristics of CHS participants at baseline $(\mathrm{n}=4,630)$ according to BMI

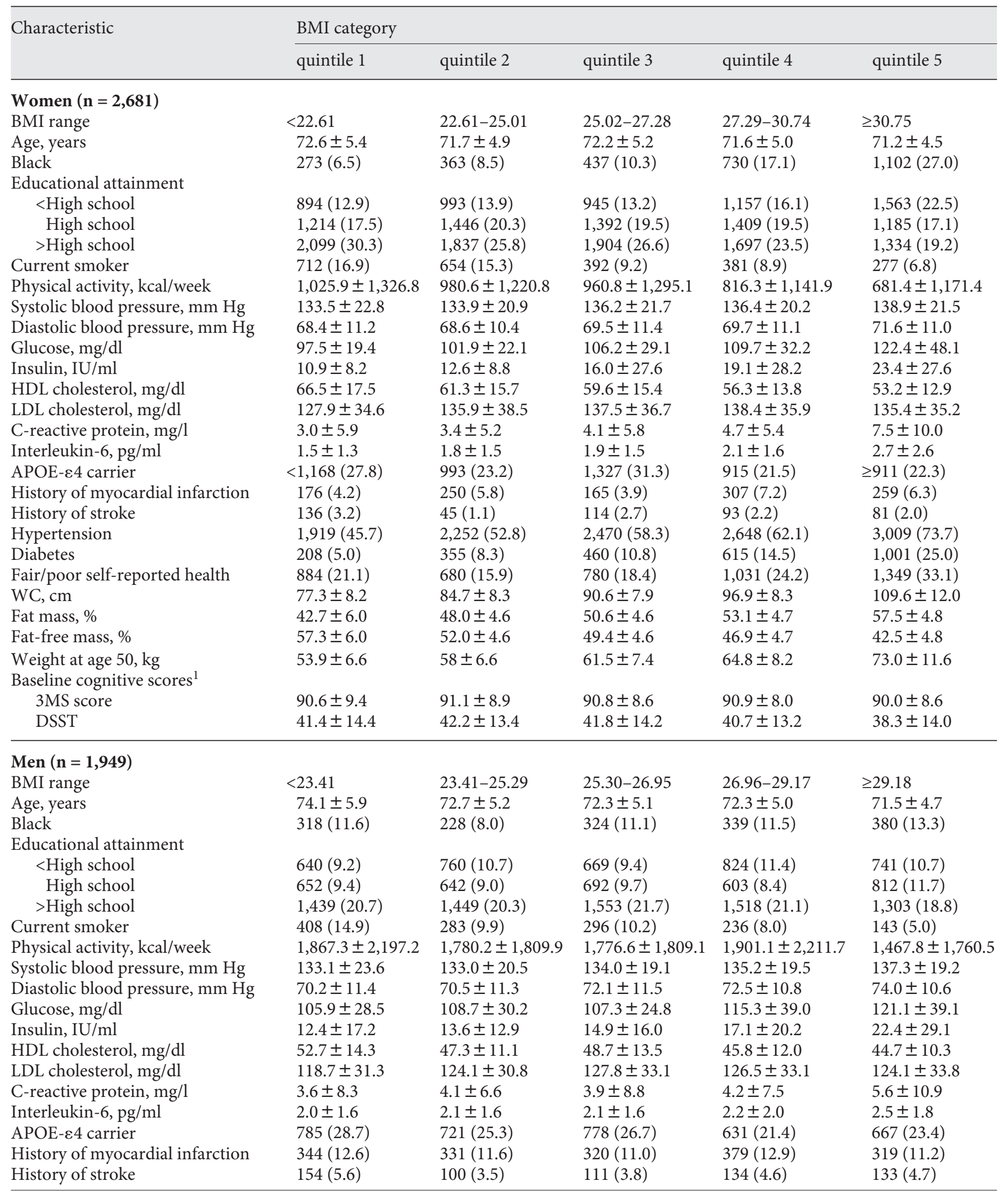


Table 1 (continued)

\begin{tabular}{|c|c|c|c|c|c|}
\hline Characteristic & \multicolumn{5}{|c|}{ BMI category } \\
\hline Diabetes & $293(10.9)$ & $386(13.6)$ & $320(11.0)$ & $516(17.7)$ & $741(26.2)$ \\
\hline Fair/poor self-reported health & $543(19.9)$ & $403(14.2)$ & $517(17.7)$ & $517(17.6)$ & $540(19.1)$ \\
\hline $\mathrm{WC}, \mathrm{cm}$ & $86.4 \pm 6.9$ & $92.9 \pm 5.1$ & $97.0 \pm 4.7$ & $100.8 \pm 5.2$ & $110.4 \pm 7.8$ \\
\hline Weight at age $50, \mathrm{~kg}$ & $68.5 \pm 7.3$ & $73.4 \pm 7.6$ & $76.2 \pm 8.6$ & $79.3 \pm 8.8$ & $85.5 \pm 12.1$ \\
\hline \multicolumn{6}{|l|}{ Baseline cognitive scores ${ }^{1}$} \\
\hline 3MS score & $87.8 \pm 10.7$ & $89.0(11.2)$ & $90.1 \pm 8.2$ & $90.0 \pm 8.4$ & $89.8 \pm 8.2$ \\
\hline DSST & $36.5 \pm 14.3$ & $37.7(14.2)$ & $38.6 \pm 13.6$ & $38.1 \pm 13.1$ & $37.5 \pm 13.6$ \\
\hline
\end{tabular}

Values are means \pm SD or numbers with percentages in parentheses.

${ }^{1}$ At 1990-1991 visit (original cohort) or 1992-1993 visit (supplemental cohort).

Table 2. General linear mixed model estimates of change in 3MS score, DSST, and a composite cognitive score over an 8-year period as a function of BMI and WC at baseline

\begin{tabular}{|c|c|c|c|c|c|c|}
\hline & \multicolumn{2}{|l|}{$3 \mathrm{MS}$} & \multicolumn{2}{|l|}{ DSST } & \multicolumn{2}{|l|}{ Composite } \\
\hline \multicolumn{7}{|l|}{ Body mass index } \\
\hline Quintile $3^{2}$ & $1.09(0.29,1.88)$ & $0.55(-0.12,1.22)$ & $1.17(-0.06,2.40)$ & $0.24(-0.71,1.20)$ & $0.17(0.02,0.31)$ & $0.06(-0.05,0.17)$ \\
\hline Quintile $4^{2}$ & $1.14(0.35,1.93)$ & $0.85(0.17,1.52)$ & $0.60(-0.63,1.82)$ & $-0.02(-0.98,0.94)$ & $0.13(-0.01,0.27)$ & $0.07(-0.04,0.18)$ \\
\hline Quintile $5^{2}$ & $0.55(-0.24,1.34)$ & $0.63(-0.06,1.32)$ & $-1.16(-2.39,0.07)$ & $-1.20(-2.18,-0.22)$ & $-0.05(-0.19,0.10)$ & $-0.03(-0.14,0.09)$ \\
\hline Quintile $3 \times$ time $^{4}$ & $0.35(0.16,0.55)$ & $0.34(0.15,0.54)$ & $0.01(-0.11,0.14)$ & $0.01(-0.12,0.13)$ & $0.01(-0.01,0.03)$ & $0.01(-0.01,0.03)$ \\
\hline Quintile $4 \times$ time $^{4}$ & $0.48(0.28,0.68)$ & $0.46(0.27,0.66)$ & $0.11(-0.02,0.24)$ & $0.10(-0.02,0.23)$ & $0.03(0.01,0.04)$ & $0.02(0.01,0.04)$ \\
\hline Quintile $5 \times$ time $^{4}$ & $0.53(0.33,0.73)$ & $0.51(0.31,0.71)$ & $0.15(0.02,0.28)$ & $0.14(0.01,0.27)$ & $0.03(0.01,0.05)$ & $0.03(0.01,0.05)$ \\
\hline \multicolumn{7}{|c|}{ Waist circumference } \\
\hline Quintile $2^{2}$ & $0.53(-0.26,1.31)$ & $0.05(-0.61,0.71)$ & $0.67(-0.54,1.89)$ & $-0.51(-1.45,0.43)$ & $0.13(-0.01,0.28)$ & $0.01(-0.10,0.11)$ \\
\hline Quintile $3^{2}$ & $0.41(-0.38,1.21)$ & $0.13(-0.54,0.80)$ & $-0.04(-1.28,1.19)$ & $-0.96(-1.91,-0.01)$ & $0.03(-0.11,0.17)$ & $-0.06(-0.17,0.05)$ \\
\hline Quintile $3 \times$ time $^{4}$ & $0.13(-0.07,0.33)$ & $0.12(-0.08,0.32)$ & $-0.01(-0.13,0.12)$ & $-0.01(-0.13,0.12)$ & $0.01(-0.01,0.04)$ & $0.01(-0.02,0.02)$ \\
\hline Quintile $4 \times$ time $^{4}$ & $0.39(0.19,0.58)$ & $0.38(0.19,0.58)$ & $0.06(-0.07,0.18)$ & $0.05(-0.07,0.18)$ & $0.02(0.01,0.04)$ & $0.02(0.01,0.04)$ \\
\hline Quintile $5 \times$ time $^{4}$ & $0.30(0.10,0.50)$ & $0.30(0.10,0.50)$ & $0.03(-0.09,0.16)$ & $0.03(-0.09,0.16)$ & $0.01(-0.01,0.03)$ & $0.01(-0.01,0.03)$ \\
\hline
\end{tabular}

1 Adjusted for age, gender, race, educational attainment (<high school, high school, >high school), field center, smoking status (never, former, current), and APOE- $\varepsilon 4$ status.

${ }^{2}$ Coefficients estimate the average difference in baseline cognitive test scores as compared with the reference group (quintile 1).

${ }^{3}$ The time coefficient estimates the annual change in cognitive scores for participants in the reference group (quintile 1).

${ }^{4}$ Coefficients estimate the average difference in cognitive scores compared to the reference group (quintile 1). 
Table 3. General linear mixed model estimates of change in 3MS score, DSST, and a composite cognitive score over an 8-year period as a function of fat mass and fat-free mass measured at baseline with BIA

\begin{tabular}{|c|c|c|c|c|c|c|}
\hline & \multicolumn{2}{|l|}{$3 \mathrm{MS}$} & \multicolumn{2}{|l|}{ DSST } & \multicolumn{2}{|l|}{ Composite } \\
\hline & unadjusted & adjusted $^{1}$ & unadjusted & adjusted $^{1}$ & unadjusted & adjusted $^{1}$ \\
\hline \multicolumn{7}{|l|}{ Fat mass } \\
\hline Quintile $2^{2}$ & $1.35(0.56,2.14)$ & $0.78(0.11,1.44)$ & $2.04(0.81,3.27)$ & $0.66(-0.30,1.61)$ & $0.29(0.14,0.43)$ & $0.14(0.03,0.25)$ \\
\hline Quintile $3^{2}$ & $1.37(0.58,2.16)$ & $0.69(0.02,1.36)$ & $2.46(1.23,3.69)$ & $0.71(-0.25,1.66)$ & $0.31(0.16,0.45)$ & $0.13(0.02,0.24)$ \\
\hline Quintile $4^{2}$ & $1.77(0.98,2.56)$ & $1.10(0.43,1.78)$ & $2.07(0.84,3.30)$ & $0.26(-0.70,1.23)$ & $0.29(0.15,0.44)$ & $0.12(0.01,0.22)$ \\
\hline Quintile $5^{2}$ & $1.47(0.68,2.26)$ & $1.21(0.52,1.89)$ & $0.90(-0.33,2.13)$ & $-0.34(-1.32,0.64)$ & $0.20(0.05,0.34)$ & $0.10(-0.01,0.21)$ \\
\hline Time $^{3}$ & $-1.28(-1.42,-1.14)$ & $-1.24(-1.38,-1.10)$ & $-0.95(-1.04,-0.85)$ & $-0.92(-1.02,-0.83)$ & $-0.12(-0.13,-0.11)$ & $-0.11(-0.13,-0.10)$ \\
\hline Quintile $2 \times$ time $^{4}$ & $0.50(0.31,0.70)$ & $0.50(0.30,0.70)$ & $0.12(-0.01,0.25)$ & $0.11(-0.02,0.24)$ & $0.02(0.01,0.04)$ & $0.02(0.01,0.04)$ \\
\hline Quintile $3 \times$ time $^{4}$ & $0.63(0.44,0.83)$ & $0.62(0.43,0.82)$ & $0.12(-0.01,0.25)$ & $0.11(-0.02,0.24)$ & $0.03(0.01,0.05)$ & $0.03(0.01,0.05)$ \\
\hline Quintile $4 \times$ time $^{4}$ & $0.69(0.50,0.89)$ & $0.68(0.48,0.88)$ & $0.17(0.04,0.30)$ & $0.16(0.03,0.29)$ & $0.04(0.02,0.06)$ & $0.04(0.02,0.06)$ \\
\hline Quintile $5 \times$ time $^{4}$ & $0.73(0.53,0.93)$ & $0.72(0.52,0.92)$ & $0.22(0.09,0.35)$ & $0.21(0.08,0.34)$ & $0.05(0.03,0.07)$ & $0.04(0.03,0.06)$ \\
\hline \multicolumn{7}{|l|}{ Fat-free mass } \\
\hline Quintile $2^{2}$ & $0.83(0.04,1.61)$ & $0.05(-0.62,0.71)$ & $2.47(1.24,3.70)$ & $0.65(-0.30,1.61)$ & $0.27(0.12,0.41)$ & $0.06(-0.05,0.17)$ \\
\hline Quintile $3^{2}$ & $2.02(1.23,2.80)$ & $0.89(0.22,1.55)$ & $3.46(2.23,4.69)$ & $1.14(0.19,2.09)$ & $0.42(0.28,0.56)$ & $0.15(0.04,0.26)$ \\
\hline Quintile $4^{2}$ & $2.04(1.25,2.83)$ & $0.89(0.22,1.56)$ & $2.81(1.58,4.03)$ & $0.52(-0.43,1.48)$ & $0.38(0.24,0.52)$ & $0.12(0.01,0.22)$ \\
\hline Quintile $5^{2}$ & $2.03(1.25,2.82)$ & $1.02(0.34,1.70)$ & $2.68(1.45,3.90)$ & $0.76(-0.21,1.73)$ & $0.36(0.21,0.50)$ & $0.13(0.02,0.24)$ \\
\hline Time $^{3}$ & $-1.06(-1.21,-0.92)$ & $-1.03(-1.17,-0.89)$ & $-0.88(-0.97,-0.78)$ & $-0.86(-0.95,-0.77)$ & $-0.11(-0.12,-0.10)$ & $-0.10(-0.12,-0.09)$ \\
\hline Quintile $2 \times$ time $^{4}$ & $0.35(0.15,0.55)$ & $0.35(0.15,0.55)$ & $0.09(-0.04,0.21)$ & $0.08(-0.05,0.21)$ & $0.02(0.00,0.04)$ & $0.02(0.00,0.04)$ \\
\hline Quintile $3 \times$ time $^{4}$ & $0.41(0.21,0.61)$ & $0.40(0.20,0.60)$ & $0.09(-0.04,0.22)$ & $0.09(-0.04,0.22)$ & $0.03(0.01,0.04)$ & $0.02(0.01,0.04)$ \\
\hline Quintile $4 \times$ time $^{4}$ & $0.33(0.13,0.53)$ & $0.33(0.13,0.53)$ & $0.02(-0.10,0.15)$ & $0.02(-0.11,0.15)$ & $0.01(-0.01,0.03)$ & $0.01(-0.01,0.03)$ \\
\hline Quintile $5 \times$ time $^{4}$ & $0.38(0.18,0.58)$ & $0.38(0.18,0.58)$ & $0.09(-0.03,0.22)$ & $0.09(-0.04,0.22)$ & $0.02(0.01,0.04)$ & $0.02(0.00,0.04)$ \\
\hline
\end{tabular}

\section{Discussion}

Adiposity measured at baseline as BMI, WC, or fat mass was inversely related with decline in $3 \mathrm{MS}$ over 8 years. A similar association was found for fat-free-mass. We observed a similar association for DSST scores in relation to BMI and fat mass.

In CHS, higher middle-age BMI is related to higher dementia risk, whereas higher older-age BMI in the same population was related to lower dementia risk [7]. This finding summarizes the existing literature, in which middle-age obesity measured with BMI is associated with dementia risk in old age $[9,10]$, whereas studies examining BMI in older age report conflicting findings [12-14, 23]. Studies examining the association between adiposity and cognitive decline show inconsistent results. In Sweden, higher middle-age BMI was related to greater composite cognitive decline [24]. In the Framingham Study, obesity was related to cognitive decline in men, but not women aged 55 years and older [25]. In the Baltimore Longitudinal study of Aging, higher BMI and waist-tohip ratio was related to worse decline in global and mem- ory tests, but with improved performance in tests of attention and visuospatial ability [26]. A study of elderly South Koreans found that obesity was related to better cognitive performance in men, but worse cognitive performance in women [27]. We found that for both sexes higher adiposity was related to better baseline performance and slower decline in the 3MS across different adiposity measures. Similar inverse associations have been reported for BMI and other outcomes such as mortality [28] and hospitalization [29] in the elderly, in whom BMI seems to be a poor adiposity measure [30]. However, we found that adiposity was inversely associated with cognitive decline whether it was measured with BIA, WC, or BMI. There was a similar association for fat-free mass. These findings suggest that both higher adiposity and lean body mass in the elderly are markers of better cognitive health. These associations were more consistent for the 3MS compared to the DSST. The DSST is a sensitive measure of frontal-executive abilities, frequently impaired by cerebrovascular disease [31], whereas global cognition captures multiple domains, including shortterm memory, most affected by neurodegenerative con- 
ditions such as Alzheimer's disease [32]. Thus, it seems reasonable to speculate that the observed associations were driven by the presence of neurodegenerative disease and not vascular disease. Our speculation is supported by the observation that weight loss precedes dementia diagnosis by decades [33].

Our results also suggest that higher adiposity in the elderly may be protective for cognition. However, higher fat mass, WC, and BMI are related to a worse metabolic and inflammatory profile in CHS [34]. We can only speculate on potential beneficial effects of adiposity on cognition. Estrogens are higher in elders with higher adiposity due to peripheral androgen conversion to estrogens, which may have cognitive benefits [35]. Leptin, elevated in obesity, may be neuroprotective [36], and higher leptin was associated with decreased dementia risk in the Framingham Study [37].

Our analyses addressed whether our findings were explained by confounding, bias, or chance. Most of our results did not change when we adjusted for covariates, or after excluding persons with cancer or smokers. Reverse causality was partially accounted by excluding persons who died within 3 years of baseline. We cannot rule out survival bias because persons with conditions that affect adiposity could have died before enrollment in CHS. In terms of chance, most of our results were consistent across multiple analyses.

\section{Conclusions}

Higher adiposity ascertained by several measures and high fat-free mass in the elderly are related to slower cognitive decline. These findings are only generalizable to the elderly population in the United States and studies in other studies are needed.

\section{Acknowledgement}

This research was supported by National Heart, Lung and Blood Institute (NHLB) contracts HHSN268201200036C, N01-HC-85239, N01-HC-85079 through N01-HC-85086; N01HC-35129, N01 HC-15103, N01 HC-55222, N01-HC-75150, N01HC-45133 and NHLBI grant HL080295, with additional contribution from the National Institute of Neurological Disorders and Stroke. Additional support was provided through AG-023629, AG-15928, AG-20098, and AG-027058 from the National Institute on Aging (see also http://www.chs-nhlbi.org/pi.htm).

\section{References}

1 Alzheimer's Association: 2011, Alzheimer's Disease Facts and Figures. Chicago, Alzheimer's Association, 2011, pp 1-68.

$\checkmark 2$ Daviglus ML, Bell CC, Berrettini W, Bowen PE, Connolly ES, Cox NJ, Dunbar-Jacob JM, Granieri EC, Hunt G, McGarry K, Patel D, Potosky AL, Sanders-Bush E, Silberberg D, Trevisan M: NIH State-of-the-Science Conference Statement: preventing Alzheimer's disease and cognitive decline. NIH Consens State Sci Statements 2010;27:1-30.

- 3 Evans DA, Funkenstein HH, Albert MS, Scherr PA, Cook NR, Chown MJ, Hebert LE, Hennekens CH, Taylor JO: Prevalence of Alzheimer's disease in a community population of older persons. Higher than previously reported. JAMA 1989;262:2551-2556.

-4 Plassman BL, Langa KM, Fisher GG, Heeringa SG, Weir DR, Ofstedal MB, Burke JR, Hurd MD, Potter GG, Rodgers WL, Steffens DC, McArdle JJ, Willis RJ, Wallace RB: Prevalence of cognitive impairment without dementia in the United States. Ann Intern Med 2008;148:427-434.

5 Luchsinger JA: Type 2 diabetes, related conditions, in relation to dementia: an opportunity for prevention? J Alzheimers Dis 2010; 20:723-736.
6 Flegal KM, Carroll MD, Ogden CL, Johnson CL: Prevalence and trends in obesity among US adults, 1999-2000. JAMA 2002;288: 1723-1727.

7 Fitzpatrick AL, Kuller LH, Lopez OL, Diehr P, O’Meara ES, Longstreth WT Jr, Luchsinger JA: Midlife and late-life obesity and the risk of dementia: cardiovascular health study. Arch Neurol 2009;66:336-342.

${ }_{8}$ Whitmer RA, Gustafson DR, Barrett-Connor E, Haan MN, Gunderson EP, Yaffe K: Central obesity and increased risk of dementia more than three decades later. Neurology 2008;71:1057-1064.

-9 Whitmer RA, Gunderson EP, Barrett-Connor E, Quesenberry CP Jr, Yaffe K: Obesity in middle age and future risk of dementia: a 27 year longitudinal population based study. BMJ 2005;330:1360.

10 Kivipelto M, Ngandu T, Fratiglioni L, Viitanen M, Kareholt I, Winblad B, Helkala EL, Tuomilehto J, Soininen H, Nissinen A: Obesity and vascular risk factors at midlife and the risk of dementia and Alzheimer disease. Arch Neurol 2005;62:1556-1560.
11 Kivipelto M, Helkala EL, Laakso MP, Hanninen T, Hallikainen M, Alhainen K, Soininen $H$, Tuomilehto J, Nissinen A: Midlife vascular risk factors and Alzheimer's disease in later life: longitudinal, population based study. BMJ 2001;322:1447-1451.

12 Gustafson D, Rothenberg E, Blennow K, Steen B, Skoog I: An 18-year follow-up of overweight and risk of Alzheimer disease. Arch Intern Med 2003;163:1524-1528.

13 Nourhashemi F, Deschamps V, Larrieu S, Letenneur L, Dartigues JF, Barberger-Gateau P, Quid PsPA: Body mass index and incidence of dementia: the PAQUID study. Neurology 2003;60:117-119.

14 Luchsinger JA, Patel B, Tang MX, Schupf N, Mayeux R: Measures of adiposity and dementia risk in elderly persons. Arch Neurol 2007;64:392-398.

15 Stewart R, Masaki K, Xue Q-L, Peila R, Petrovitch H, White LR, Launer LJ: A 32-year prospective study of change in body weight and incident dementia: the Honolulu-Asia Aging Study. Arch Neurol 2005;62:55-60.

- 16 Tell GS, Fried LP, Hermanson B, Manolio TA, Newman AB, Borhani NO: Recruitment of adults 65 years and older as participants in the Cardiovascular Health Study. Ann Epidemiol 1993;3:358-366. 
$>17$ Fried LP, Borhani NO, Enright P, Furberg CD, Gardin JM, Kronmal RA, Kuller LH, Manolio TA, Mittelmark MB, Newman A, et al: The Cardiovascular Health Study: design and rationale. Ann Epidemiol 1991;1:263276.

18 Deurenberg P, van der Kooy K, Hautvast JG: The assessment of the body composition in the elderly by densitometry, anthropometry and bioelectrical impedance. Basic Life Sci 1990;55:391-393.

19 Teng EL, Chui HC: The Modified MiniMental State (3MS) examination. J Clin Psychiatry 1987;48:314-318.

20 Brandt J, Spence M, Folstein M: The Telephone Interview for Cognitive Status. Neuropsychiatry Neuropsychol Behav Neurol 1988;1:111-117.

-21 Hixson JE, Vernier DT: Restriction isotyping of human apolipoprotein $\mathrm{E}$ by gene amplification and cleavage with HhaI. J Lipid Res 1990;31:545-548.

22 Arnold AM, Newman AB, Dermond N, Haan M, Fitzpatrick A: Using telephone and informant assessments to estimate missing Modified Mini-Mental State Exam scores and rates of cognitive decline. The Cardiovascular Health Study. Neuroepidemiology 2009;33:55-65.

23 Nourhashemi F, Deschamps V, Larrieu S, Letenneur L, Dartigues J-F, Barberger-Gateau P: Body mass index and incidence of dementia: The PAQUID study. Neurology 2003;60:117-119.
24 Dahl A, Hassing LB, Fransson E, Berg S, Gatz M, Reynolds CA, Pedersen NL: Being overweight in midlife is associated with lower cognitive ability and steeper cognitive decline in late life. J Gerontol A Biol Sci Med Sci 2010;65:57-62.

25 Elias MF, Elias PK, Sullivan LM, Wolf PA, D'Agostino RB: Obesity, diabetes and cognitive deficit: the Framingham Heart Study. Neurobiol Aging 2005;26(suppl 1):11-16.

26 Gunstad J, Lhotsky A, Wendell CR, Ferrucci L, Zonderman AB: Longitudinal examination of obesity and cognitive function: results from the Baltimore longitudinal study of aging. Neuroepidemiology 2010;34:222229.

27 Han C, Jo SA, Seo JA, Kim BG, Kim NH, Jo I, Park MH, Park KW: Adiposity parameters and cognitive function in the elderly: application of 'Jolly Fat' hypothesis to cognition. Arch Gerontol Geriatr 2009;49:e133-e138.

-28 Stevens J, Cai J, Pamuk ER, Williamson DF, Thun MJ, Wood JL: The effect of age on the association between body-mass index and mortality. N Engl J Med 1998;338:1-7.

29 Luchsinger JA, Lee WN, Carrasquillo O, Rabinowitz D, Shea S: Body mass index and hospitalization in the elderly. J Am Geriatr Soc 2003;51:1615-1620.

30 Heiat A, Vaccarino V, Krumholz HM: An evidence-based assessment of federal guidelines for overweight and obesity as they apply to elderly persons. Arch Intern Med 2001; 161:1194-1203.
31 Hachinski V, Iadecola C, Petersen RC, Breteler MM, Nyenhuis DL, Black SE, Powers WJ, DeCarli C, Merino JG, Kalaria RN, Vinters HV, Holtzman DM, Rosenberg GA, Dichgans M, Marler JR, Leblanc GG: National Institute of Neurological Disorders and Stroke-Canadian Stroke Network vascular cognitive impairment harmonization standards. Stroke 2006;37:2220-2241.

32 Cummings JL: Alzheimer's Disease. N Engl J Med 2004;351:56-67.

33 Knopman DS, Edland SD, Cha RH, Petersen $\mathrm{RC}$, Rocca WA: Incident dementia in women is preceded by weight loss by at least a decade. Neurology 2007;69:739-746.

- 34 Biggs ML, Mukamal KJ, Luchsinger JA, Ix $\mathrm{JH}$, Carnethon MR, Newman AB, de Boer IH, Strotmeyer ES, Mozaffarian D, Siscovick DS: Association between adiposity in midlife and older age and risk of diabetes in older adults. JAMA 2010;303:2504-2512.

35 Yaffe K, Barnes D, Lindquist K, Cauley J, Simonsick EM, Penninx B, Satterfield S, Harris T, Cummings SR: Endogenous sex hormone levels and risk of cognitive decline in an older biracial cohort. Neurobiol Aging 2007;28:171-178.

36 Signore AP, Zhang F, Weng Z, Gao Y, Chen $\mathrm{J}$ : Leptin neuroprotection in the CNS: mechanisms and therapeutic potentials. J Neurochem 2008;106:1977-1990.

37 Lieb W, Beiser AS, Vasan RS, Tan ZS, Au R, Harris TB, Roubenoff R, Auerbach S, DeCarli C, Wolf PA, Seshadri S: Association of plasma leptin levels with incident Alzheimer disease and MRI measures of brain aging. JAMA 2009;302:2565-2572. 